Original Research Reports

\title{
The Meaning of Respect Under Varying Context Conditions
}

\author{
Christoph Daniel Schaefer ${ }^{1}$, Steffen Zitzmann ${ }^{2}$, Lukas Loreth ${ }^{1}$, Julian Paffrath ${ }^{1}$, Hilmar Grabow ${ }^{1}$, Michael Loewy ${ }^{3}$, \\ Bernd Simon ${ }^{1}$
}

[1] Tolerance Research Unit Kiel, Kiel University, Kiel, Germany. [2] Hector Research Institute of Education Sciences and Psychology, University of Tübingen, Tübingen, Germany. [3] California School of Professional Psychology, Alliant International, Emeryville, CA, USA.

Journal of Social and Political Psychology, 2021, Vol. 9(2), 536-552, https://doi.org/10.5964/jspp.7313

Received: 2020-08-12 • Accepted: 2021-06-13 • Published (VoR): 2021-10-29

Handling Editor: Johanna Vollhardt, Clark University, Worcester, MA, USA

Corresponding Author: Christoph Daniel Schaefer, Faculty of Business Management and Social Sciences, Osnabrück University of Applied Sciences, P.O Box 19 40, D-49009 Osnabrück, Germany. E-mail: schaefer@psychologie.uni-kiel.de

Supplementary Materials: Materials [see Index of Supplementary Materials]

\begin{abstract}
The concept of respect figures prominently in several theories on intergroup relations. Previous studies suggested that the experience of being respected is primarily related to the feeling of being recognized as an equal, as opposed to social recognition of needs or achievements. Those studies focused, however, on either minority groups or ad hoc groups, thereby possibly giving equality recognition an advantage. This article extends previous findings by comparing societal groups situated in various contexts. We examined eight groups from four countries. We anticipated and found that the link between respect and equality recognition was stronger for groups that are in the position of minorities compared to groups associated with majorities. Owing to the moral and legal force of the norm of equality, disadvantaged minorities in particular might be able to improve their societal position by founding their claims on the equality principle. Need recognition, in contrast, was less influential for minority groups than for majority groups. While we observed these context-dependent variations, an internal meta-analysis showed that feeling recognized as an equal was, overall, the strongest indicator for feeling respected. This suggests that demands for respect could often be addressed by establishing relationships in society that are based on mutual recognition as equals, while the implications of achievement and need recognition should additionally be considered in specific contexts.
\end{abstract}

\section{Keywords}

respect, equality recognition, minorities, majorities, social protest

Due to modernization, secularization and globalization processes, numerous societies are subjected to an increasing degree of ethnic, cultural, and religious pluralism. This heterogeneity of (post-)modern societies entails that members of various societal groups claim recognition for their place in society (Honneth, 1995; Parekh, 2008; Simon, 2017; Simon, Reininger, Schaefer, Zitzmann, \& Krys, 2019). In the context of social protest and discontent, societal groups' claims have frequently crystallized as references to disrespect (Honneth, 2003) and been articulated as demands for respect (Simon \& Grabow, 2014). For a better understanding of these demands, it is pertinent to investigate the meaning of respect from the perspectives of the members of societal groups. This article aims to shed light on the experiences of being respected and being recognized in different intergroup contexts.

On the conceptual level, a prominent understanding of respect has been derived from Kant's moral philosophy. This philosophy demands that we do not reduce others to mere means to our own ends. Since all rational beings possess dignity, all deserve consideration as equals (Kant, 1785/1974). This consideration as equals constitutes a universalised 
form of respect that is detached from personal relationships and subgroup identifications. Such a conception of respect has been highly influential, so that in the domain of moral philosophy respect is widely understood as being owed universally to every human being (Fraser, 2003).

This egalitarian understanding informs the recognition framework proposed by Honneth (1995, 2003). Building on Hegel (e.g., 1805-1806/1969), three types of social relations in modern society are distinguished by Honneth (1995, 2003), each of which is primarily governed by its own normative principle. On the basis of these normative principles, individuals are morally entitled to certain kinds of recognition. The spheres and especially the principles named by Honneth (1995) are similar to (and overlapping with) those identified by Deutsch (1975). In the taxonomy of Honneth (1995), the first sphere is constituted by close personal relationships, which are shaped by loving care. Here, the need principle gets priority, to the effect that these relations are guided by an orientation towards (and by a justified expectation of) the fulfilment of individual needs. In the second sphere, made up by legal and political relations, recognition is embodied by laws and rights, while the equality principle has priority, according to which people are universally entitled to being respected by others as equals, due to their moral autonomy. Third, with a view of society as a system of cooperative relations, individual varieties of self-realization are recognized on the basis of the merit or achievement principle, so that recognition is conveyed to the degree that a person's individual achievements contribute to the values and goals of society (Honneth, 1995, 2003). Together, the realisation of these principles in society is assumed to give individuals the opportunity to follow freely chosen aims in life (Honneth, 2001). According to Honneth (2001), there is an internal connection between morality and recognition, insofar as the denial of a relevant recognition principle leads to experiences of moral offence and injustice. This feeling of a moral injustice consists of the view that an action intentionally disregarded a central aspect of one's personal wellbeing, therefore having the potential of unfolding struggles for recognition (Honneth, 2001, 2003).

The threefold taxonomy of recognition principles provides a useful conceptual framework for empirically examining the phenomenology of respect. Previous work has consequently examined to what degree the concept of respect is empirically linked, in the perception of social group members, to the three recognition principles oriented towards needs, equality, and merit or achievement (Simon \& Grabow, 2014; Simon, Grabow, \& Böhme, 2015). Since the concept of respect is widely used in moral philosophy to describe the recognition to which human beings are equally entitled (Fraser, 2003), and since social movements often refer to their experiences of disrespect in their struggles for societal recognition, previous research assumes a close relationship between the perception of being respected and being treated as equals (Renger \& Simon, 2011; Simon \& Grabow, 2014; Simon et al., 2015). This previous research tested to what degree the conception of respect as being treated equally corresponds to empirical experiences of being respected.

The present research aims at expanding this previous research by examining the experience of being respected in different societal contexts. By sampling members of societal groups that are situated in various intergroup settings, the present research carves out commonalities and differences in the meaning of respect across contexts. A better grasp of the core of the demands for respect in socio-political group struggles further contributes to accessing the internal logic of these struggles, elucidating motivations, as well as pointing to potential societal responses that could satisfy these demands.

Previous experimental research that examined the interrelationship and effects of equality recognition and respect was situated in a setting of (artificial) ad hoc groups (Renger \& Simon, 2011). It induced participants' feelings of being recognized through messages from alleged fellow group members. Of particular relevance for the question of the meaning of respect is the finding that participants' feelings of being respected was a function of their feeling of being recognized as an equal (Renger \& Simon, 2011).

In addition to experimental work, previous research with members of societal groups also demonstrates the link between respect and equality recognition. It was studied to which degree minority group members felt respected and recognized by the societal majority (Simon \& Grabow, 2014; Simon et al., 2015). When relating the feeling of being respected to the feeling of being recognized, the feeling of respect was more strongly associated with equality recognition than with achievement recognition or need recognition, thus confirming the link observed in the preceding experimental studies. 


\section{The Present Research}

With regard to the previous research reviewed above, it could be argued that the investigated groups were situated in contexts that were especially prone to giving equality recognition an advantage relative to the other recognition principles. Regarding the laboratory ad hoc groups, there was - beyond the equality messages - no individuating information about the alleged fellow group members or about the group provided. Consequently, there was hardly any basis for the other recognition principles to unfold. Minority members surveyed by Simon and Grabow (2014), on the other hand, may have been particularly sensitive to equality recognition due to past discrimination experiences and, thus, the right to non-discrimination in the form of equal treatment was probably highly salient. Therefore, group members' sensitivity to the (lack of) equal treatment might colour these group members' demands, in the sense that behind the demands for respect might lie demands for equality recognition.

The present research examines to what degree the conceptual association between equality recognition and respect emerges empirically for a broader spectrum of societal groups than previously researched. The broad sampling of groups which are situated in various intergroup contexts enabled us to conduct moderation analyses and an internal meta-analysis. Our studies spanned four countries and covered groups representing both the traditional pole and the (post-)modern pole of societies (see Inglehart \& Norris, 2003). We included both minority groups and groups that are associated with the respective societal majority.

\section{Research Questions}

Compared to majority groups, it is more likely that minority groups lack - and therefore have to fight for - equality recognition. We expected that minority group members' concern for equality recognition angles their demands for respect and their understanding of respect. Members of majority groups, in contrast, can typically take their place in society for granted (Licata, Sanchez-Mazas, \& Green, 2011; Simon, 2004); therefore they may be less attentive to equality recognition than members of minority groups. Since majorities often have a privileged position compared to minorities, they can profit little from claims of being treated equal to minorities. We therefore hypothesised that the link between equality recognition and respect would be stronger for minority groups than for groups associated with majorities.

As majority groups often have an interest in defending their privileged place in society (Dovidio, Gaertner, \& Saguy, 2007), we also anticipated that for them achievement recognition would gain importance, since references to achievement might function as a justification for their superior social status and associated privileges. By claiming that majority members are more successful in contributing to societal aims, they could construe a basis for justifying their privileges. While members of majority groups tend to regard the larger society as representing their group's values (Dovidio et al., 2007) - and while, according to Honneth $(1995,2003)$, achievement recognition is awarded in relation to societal values - members of majority groups could see themselves in a justified position for claiming achievement recognition. Since a traditional understanding of respect implies status recognition (see Honneth, 1995) and since members of majorities might perceive their privileges as justified by their societal achievements, we assumed that this role of achievements could translate into a connection between claims of respect and claims for achievement recognition. We therefore hypothesised that the link between achievement recognition and respect is stronger for members of majorities than for members of minorities.

\section{The Present Research in Relation to Previous Research on Differences Between Minorities and Majorities}

Previous research found differences between minority and majority group members that are compatible with these predictions. When members of minorities and majorities were, for example, confronted with the choice between being respected and being liked, minority group members had a stronger preference for being respected than majority members (Bergsieker, Shelton, \& Richeson, 2010). This result points in a similar direction as our predictions, insofar as it suggests that minority group members are more sensitive to being respected. When this result is viewed in combination with the preliminary finding that respect can imply equality recognition, then the importance of being respected indicated by minorities suggests a higher sensitivity to their position in society, compared with majority group members. Thus, minorities' preference for being respected might be an expression of an implied link between respect and equality recognition. 
The finding that majority group members had a stronger preference for being liked than minority group members is similar to a result of Aydin, Ullrich, Siem, Locke, and Shnabel (2019), indicating that members of groups who believed that they had undeserved advantages wanted to appear warm and trustworthy. These preferences of majority group members for appearing likable might translate into a stronger link between respect and need recognition (compared to minority group members). A relationship between a preference for being liked and the meaning of respect, however, is not self-evident. While both equality recognition and achievement recognition are located at the societal level, need recognition is based on personal relationships, according to Honneth (1995). It therefore cannot be taken for granted that there is a close connection between feeling liked and feeling respected on the societal level. We therefore did not venture a hypothesis about a minority-majority difference regarding the relationship between respect and need recognition, though we acknowledge the possibility of a stronger relationship between these two constructs among majority group members.

Supplementing the findings on differences between majority and minority groups, research indicated differences between the preferences of people who were victimized through harsh or unfair treatment and the preferences of the perpetrators (i.e., those who treated others harshly or unfairly; Shnabel \& Nadler, 2008). Those who were treated harshly stated a higher preference for having control and influence, compared to the perpetrators. Similarly, Aydin et al. (2019) found that members of groups who felt victimized wanted to appear assertive. These results are in line with our assumption that minority group members, by having a higher likelihood of being threatened by discrimination, have a higher sensitivity to their position in society than majority group members. These previous results, however, did not address the question of the different meaning of respect, and provide only indirect cues for the importance of equality recognition for minority members. Our study, in contrast, allows us to analyse and directly compare the meaning of respect for several social groups.

\section{Summary of the Present Research's Contribution}

By sampling groups with various societal positions and in diverse national settings, we put the hypothesised equality recognition-respect link to a stringent empirical test. We examined the relative strengths of the link between equality recognition and respect vis-à-vis the link between achievement recognition and respect and that between need recognition and respect. We compared these links within as well as across samples of minority and majority groups to arrive at a more comprehensive picture on how the minority or majority position of a group affects the phenomenology of respect. We also conducted moderation analyses to examine whether respect was differently related to equality and achievement recognition for majority groups in comparison with minority groups. Additionally, we conducted an internal meta-analysis to obtain overall measures of the links between respect and recognition principles across our samples. In all analyses, we included demographic variables as control variables.

By examining the meaning of respect among minority and majority groups, our research goes beyond previous research that had a less precise definition of respect and implied that the meaning of respect is monolithic. When Bergsieker et al. (2010), for example, compared the importance of respect and liking for minority and majority members, it was assumed that minority and majority group members understand respect in the same way.

In summary, the novelty of our research is based on the sampling across a broad array of intergroup contexts, which enabled us to conduct moderation analyses for examining differences in the meanings of respect across contexts. The results of these analyses on the contextual meaning of respect also imply a better and more nuanced understanding of group members' claims for respect that are involved in intergroup struggles.

\section{Method}

\section{Respondents}

As part of a larger research project concerning life in pluralistic societies, eight samples were recruited. To ensure that groups across a broad societal spectrum were sampled, both groups with a religious or traditional orientation and groups with a liberal or progressive orientation were sampled. 
For the comparisons between minority and majority groups, we categorized five samples as minority groups and the remaining three as being associated with the majorities of the respective societies. Sampled groups associated with majority groups were Tea Party supporters in the United States, Catholics in Poland, and Protestants in Germany. Catholics in Poland constituted the most obvious case of a majority, as this group is both numerically and culturally dominant (Porter-Szűcs, 2011). We also assigned Protestants in Germany and Tea Party supporters in the United States to this category, as both groups are associated with the dominant cultural group in their respective societies. Under the category of minority groups, we subsumed the remaining five groups, namely Protestants in Brazil, Muslims and Alevis ${ }^{1}$ in Germany, members of the LGBTI ${ }^{2}$ community in Germany and members of the LGBT community in the United States.

Details for these eight samples are presented in Table 1, including the number of participants, the specific period of data collection, and socio-demographic information. These samples had been used in previous research to address research questions different from the research question of the present article (Paffrath \& Simon, 2020; Schaefer \& Simon, 2020; Simon \& Schaefer, 2016, 2018; Simon, Eschert, Schaefer, Reininger, Zitzmann, \& Smith, 2019; Simon et al., 2019; Zitzmann, Loreth, Reininger, \& Simon, 2021). However, the main data analyses reported in this article are novel and have not been published elsewhere.

\section{Procedure}

Data were predominantly collected with web-based questionnaires, while a small portion of some samples was collected through paper-and-pencil versions of the questionnaires. Potential respondents were contacted through mailing lists of various institutions (notably universities, religious organizations, religious communities, and organizations associated with LGBT/LGBTI communities), through internet advertisement, or through the market research companies Qualtrics and SSI/dynata. In all cases, full anonymity was ensured.

\section{Measures}

In addition to sociodemographic information, respondents provided ratings for the respect and recognition scales. All rating scales were accompanied by a no-answer option, the selection of which was treated as a missing value.

The measures of social recognition (i.e., equality recognition, achievement recognition, and need recognition) were adapted from earlier work on social recognition processes (Simon \& Grabow, 2014). To assess the experience of being recognized as equals by the larger society, participants were asked whether members of their group are recognized as equal fellow citizens by the (respective national) population in general. We listed several social groups in these items, but only one item per sample asked for the population in general. (For example, for Tea Party supporters it read: "Are Tea Party supporters recognized as equal fellow citizens by the following groups?" - "by the U.S. population in general?" The other social groups listed were societal subgroups and specific to the samples.) To measure achievement recognition, we used one item to ask respondents whether the contributions that members of their ingroup make to society are regarded as valuable by the respective population in general (e.g., "Are the contributions that Tea Party supporters make to U.S. society regarded as valuable by the following groups?"). Need recognition was assessed by asking for respondents' ratings of the extent to which the respective population in general cares about or recognizes what members of the respondents' group need (e.g., "Do the following groups care about what Tea Party supporters need?"). To gauge perceived respect, respondents rated the extent to which members of their ingroup are respected by the general population (e.g., "Are Tea Party supporters respected by the following groups?”). The phrasing of the items in the samples is listed in the online Appendix A (see Supplementary Materials).

Response scales varied somewhat between the various samples, due to the different research contexts and adjustments over time. However, for all recognition measurements, a 5-point-scale was used for all samples.

1) Alevism is a religious belief system with mystic elements (see Kaplan, 2013).

2) We use the terms "LGBTI" and "LGBT" in this article in the way they were used in the respective questionnaires in Germany and the United States. 


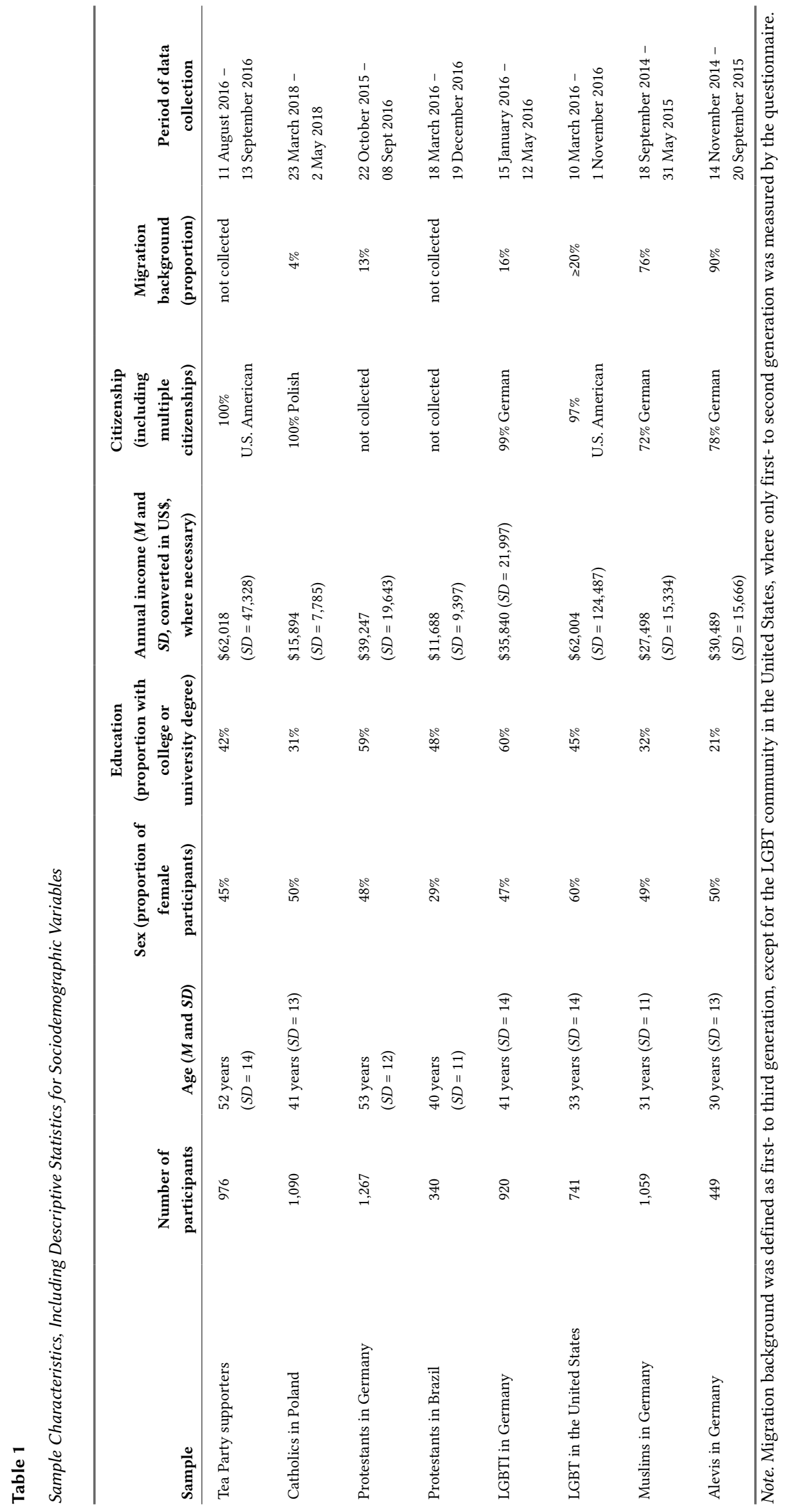

Journal of Social and Political Psychology 


\section{Results}

Means, standard deviations, and correlations for all variables are presented in the online Appendix B (see Supplementary Materials). In our statistical analyses, we compared the links between respect and equality recognition, between respect and achievement recognition, and between respect and need recognition. We conducted three classes of statistical analyses.

We firstly conducted comparisons within each of the sampled groups separately. We examined whether the strength of the link between perceived respect and equality recognition was stronger than the links between respect and the other two recognition principles within each group. Secondly, we combined our eight samples by an internal meta-analysis for an overall picture, thereby addressing the question whether, overall, respect was more closely linked to equality recognition than to achievement or need recognition. Finally, we analysed the minority groups as one set of groups and the groups associated with majorities as another set of groups, treating each set as a whole. We conducted comparisons between these sets of groups, testing whether the link between respect and equality recognition was stronger for minority groups than for majority groups. We also tested whether there were differences between minority groups and majority groups regarding the links between respect and achievement recognition or need recognition.

\section{Comparisons of the Links Between Respect and Recognition Principles Within the Sampled Groups}

We examined the extent to which perceived respect was associated with each of the three recognition principles. We used respect as a criterion in multiple regressions with the three recognition principles as simultaneous predictors. We tested whether the regression coefficients for the recognition principles were significantly different from one another (within each of the sampled groups).

We ran a multiple regression analysis for each of the sampled groups. As sociodemographic control variables, we included age, gender (coded as 0 for female and 1 for male), education (coded as 0 for respondents without a university or college degree and 1 for respondents with a university or college degree), and net income. All variables were $z$-standardized, for better comparability of samples with differing scale formats. In the resulting eight regression analyses $\left(R^{2} \mathrm{~s} \geq .23, \mathrm{SEs} \leq .025, \mathrm{ps}<.001\right)$, the three principles of perceived recognition received a significant and positive regression weight in all samples except for one ( $p s \leq .013$; the exception was need recognition for Alevis, $p=.129$ ). The coefficients of these regression analyses are presented in Table 2.

We compared the regression coefficients for the principles of recognition within each of the samples. For all samples except one, perceived recognition of one's equality emerged descriptively as the strongest predictor for respect (see Table 2; the exception was Protestants in Germany).

To assess the statistical significance of these differences between the recognition principles as predictors for respect, we calculated differences for each sample by subtracting the regression coefficient of achievement recognition or need recognition, respectively, from the coefficient of equality recognition. Inferential statistics of these difference scores (computed with Mplus, Muthén \& Muthén, 1998-2010) are displayed in Table 3. 
Table 2

Multiple Regression Analyses With Perceived Respect as the Criterion

\begin{tabular}{|c|c|c|c|c|}
\hline Predictor / Sample & $\boldsymbol{b}$ & $S E$ & $t$ & $p$ \\
\hline \multicolumn{5}{|l|}{ Equality recognition } \\
\hline Catholics in Poland ${ }^{\mathrm{a}}$ & 0.411 & 0.032 & 12.774 & $<.001$ \\
\hline Protestants in Germany ${ }^{\mathrm{b}}$ & 0.200 & 0.030 & 6.689 & $<.001$ \\
\hline Tea Party supporters ${ }^{c}$ & 0.296 & 0.038 & 7.790 & $<.001$ \\
\hline Protestants in Brazil ${ }^{\mathrm{d}}$ & 0.280 & 0.061 & 4.618 & $<.001$ \\
\hline Muslims in Germany ${ }^{\mathrm{e}}$ & 0.443 & 0.032 & 13.841 & $<.001$ \\
\hline Alevis in Germany ${ }^{\mathrm{f}}$ & 0.394 & 0.054 & 7.289 & $<.001$ \\
\hline LGBTI in Germany ${ }^{\mathrm{g}}$ & 0.340 & 0.035 & 9.723 & $<.001$ \\
\hline LGBT in the United States ${ }^{\mathrm{h}}$ & 0.320 & 0.043 & 7.409 & $<.001$ \\
\hline \multicolumn{5}{|l|}{ Achievement recognition } \\
\hline Catholics in Poland $^{\mathrm{a}}$ & 0.212 & 0.031 & 6.839 & $<.001$ \\
\hline Protestants in Germany ${ }^{\mathrm{b}}$ & 0.310 & 0.032 & 9.635 & $<.001$ \\
\hline Tea Party supporters ${ }^{c}$ & 0.215 & 0.042 & 5.070 & $<.001$ \\
\hline Protestants in Brazil ${ }^{\mathrm{d}}$ & 0.158 & 0.064 & 2.480 & .013 \\
\hline Muslims in Germany ${ }^{\mathrm{e}}$ & 0.218 & 0.034 & 6.395 & $<.001$ \\
\hline Alevis in Germany ${ }^{\mathrm{f}}$ & 0.202 & 0.062 & 3.258 & .001 \\
\hline LGBTI in Germany $^{\mathrm{g}}$ & 0.241 & 0.033 & 7.214 & $<.001$ \\
\hline LGBT in the United States ${ }^{\mathrm{h}}$ & 0.243 & 0.045 & 5.431 & $<.001$ \\
\hline \multicolumn{5}{|l|}{ Need recognition } \\
\hline Catholics in Poland ${ }^{\mathrm{a}}$ & 0.172 & 0.032 & 5.335 & $<.001$ \\
\hline Protestants in Germany ${ }^{\mathrm{b}}$ & 0.262 & 0.032 & 8.221 & $<.001$ \\
\hline Tea Party supporters ${ }^{c}$ & 0.180 & 0.040 & 4.454 & $<.001$ \\
\hline Protestants in Brazil ${ }^{\mathrm{d}}$ & 0.166 & 0.061 & 2.695 & .007 \\
\hline Muslims in Germany ${ }^{\mathrm{e}}$ & 0.131 & 0.031 & 4.193 & $<.001$ \\
\hline Alevis in Germany ${ }^{\mathrm{f}}$ & 0.088 & 0.058 & 1.520 & .129 \\
\hline LGBTI in Germany ${ }^{\mathrm{g}}$ & 0.204 & 0.033 & 6.119 & $<.001$ \\
\hline LGBT in the United States $^{\mathrm{h}}$ & 0.179 & 0.044 & 4.053 & $<.001$ \\
\hline \multicolumn{5}{|l|}{ Age } \\
\hline Catholics in Poland ${ }^{\mathrm{a}}$ & 0.059 & 0.025 & 2.307 & .021 \\
\hline Protestants in Germany ${ }^{\mathrm{b}}$ & 0.055 & 0.027 & 2.049 & .040 \\
\hline Tea Party supporters ${ }^{c}$ & 0.057 & 0.029 & 1.963 & .050 \\
\hline Protestants in Brazil ${ }^{\mathrm{d}}$ & 0.050 & 0.055 & 0.912 & .362 \\
\hline Muslims in Germany ${ }^{\mathrm{e}}$ & -0.089 & 0.027 & -3.323 & .001 \\
\hline Alevis in Germany ${ }^{\mathrm{f}}$ & -0.070 & 0.048 & -1.442 & .149 \\
\hline LGBTI in Germany ${ }^{g}$ & 0.002 & 0.028 & 0.082 & .934 \\
\hline LGBT in the United States ${ }^{\mathrm{h}}$ & 0.024 & 0.037 & 0.655 & .512 \\
\hline \multicolumn{5}{|l|}{ Gender/Sex } \\
\hline Catholics in Poland ${ }^{\mathrm{a}}$ & 0.021 & 0.026 & 0.810 & .418 \\
\hline Protestants in Germany ${ }^{\mathrm{b}}$ & -0.046 & 0.028 & -1.655 & .098 \\
\hline Tea Party supporters ${ }^{\mathrm{c}}$ & 0.015 & 0.029 & 0.494 & .621 \\
\hline Protestants in Brazil ${ }^{\mathrm{d}}$ & -0.048 & 0.052 & -0.926 & .355 \\
\hline Muslims in Germany ${ }^{\mathrm{e}}$ & 0.023 & 0.025 & 0.895 & .371 \\
\hline Alevis in Germany ${ }^{\mathrm{f}}$ & 0.010 & 0.048 & 0.202 & .840 \\
\hline LGBTI in Germany ${ }^{\mathrm{g}}$ & 0.015 & 0.027 & 0.551 & .582 \\
\hline LGBT in the United States ${ }^{\mathrm{h}}$ & -0.007 & 0.036 & -0.183 & .855 \\
\hline
\end{tabular}




\begin{tabular}{|c|c|c|c|c|}
\hline Predictor / Sample & $b$ & $S E$ & $t$ & $p$ \\
\hline \multicolumn{5}{|l|}{ Education } \\
\hline Catholics in Poland ${ }^{\mathrm{a}}$ & 0.021 & 0.025 & 0.830 & .406 \\
\hline Protestants in Germany ${ }^{\mathrm{b}}$ & -0.044 & 0.028 & -1.563 & .118 \\
\hline Tea Party supporters ${ }^{c}$ & -0.036 & 0.030 & -1.192 & .233 \\
\hline Protestants in Brazil ${ }^{\mathrm{d}}$ & 0.056 & 0.056 & 0.998 & .318 \\
\hline Muslims in Germany ${ }^{e}$ & 0.005 & 0.026 & 0.195 & .845 \\
\hline Alevis in Germany ${ }^{f}$ & 0.083 & 0.044 & 1.874 & .061 \\
\hline LGBTI in Germany ${ }^{\mathrm{g}}$ & 0.006 & 0.027 & 0.219 & .827 \\
\hline LGBT in the United States ${ }^{\mathrm{h}}$ & 0.019 & 0.034 & 0.546 & .585 \\
\hline \multicolumn{5}{|l|}{ Income } \\
\hline Catholics in Poland ${ }^{\mathrm{a}}$ & 0.035 & 0.026 & 1.320 & .187 \\
\hline Protestants in Germany ${ }^{\mathrm{b}}$ & -0.005 & 0.029 & -0.166 & .868 \\
\hline Tea Party supporters ${ }^{c}$ & 0.037 & 0.030 & 1.240 & .215 \\
\hline Protestants in Brazil $^{\mathrm{d}}$ & -0.017 & 0.057 & -0.305 & .760 \\
\hline Muslims in Germany ${ }^{e}$ & -0.010 & 0.026 & -0.368 & .713 \\
\hline Alevis in Germany ${ }^{\mathrm{f}}$ & -0.045 & 0.045 & -1.010 & .313 \\
\hline LGBTI in Germany ${ }^{\mathrm{g}}$ & 0.063 & 0.028 & 2.270 & .023 \\
\hline LGBT in the United States ${ }^{\mathrm{h}}$ & 0.004 & 0.034 & 0.120 & .905 \\
\hline
\end{tabular}

Note. For respect and the principles of recognition, higher scores indicate a higher level of the construct in question. Age was measured in years.

Gender/sex was coded into female (0) and male (1). Education was coded into without university/college degree (0) and with university/college degree (1). All variables were $z$-standardized, for better comparability. All $p$-values are for two-tailed tests.

${ }^{\mathrm{a}} R^{2}=.454(p<.001) .{ }^{\mathrm{b}} R^{2}=.373(p<.001) .{ }^{\mathrm{c}} R^{2}=.357(p<.001) .{ }^{\mathrm{d}} R^{2}=.234(p<.001) .{ }^{\mathrm{e}} R^{2}=.480(p<.001) .{ }^{\mathrm{f}} R^{2}=.368(p<.001) .{ }^{\mathrm{g}} R^{2}=.472(p<.001)$.

${ }^{\mathrm{h}} R^{2}=.402(p<.001)$.

\section{Table 3}

Differences Between the Standardized Regression Coefficients: Equality Recognition Minus Achievement Recognition Coefficients and Equality Recognition Minus Need Recognition Coefficients

\begin{tabular}{|c|c|c|c|c|}
\hline Difference between coefficients / Sample & $\Delta b$ & $S E$ & $t$ & $p$ \\
\hline \multicolumn{5}{|c|}{ Equality recognition minus achievement recognition } \\
\hline Catholics in Poland & 0.199 & 0.052 & 3.863 & $<.001$ \\
\hline Protestants in Germany & -0.110 & 0.048 & -2.309 & .021 \\
\hline Tea Party supporters & 0.081 & 0.066 & 1.224 & .221 \\
\hline Protestants in Brazil & 0.123 & 0.101 & 1.215 & .225 \\
\hline Muslims in Germany & 0.226 & 0.056 & 4.006 & $<.001$ \\
\hline Alevis in Germany & 0.192 & 0.097 & 1.972 & .049 \\
\hline LGBTI in Germany & 0.099 & 0.057 & 1.724 & .085 \\
\hline LGBT in the United States & 0.076 & 0.072 & 1.063 & .288 \\
\hline \multicolumn{5}{|l|}{ Equality recognition minus need recognition } \\
\hline Catholics in Poland & 0.239 & 0.054 & 4.447 & $<.001$ \\
\hline Protestants in Germany & -0.062 & 0.050 & -1.253 & .210 \\
\hline Tea Party supporters & 0.116 & 0.063 & 1.824 & .068 \\
\hline Protestants in Brazil & 0.115 & 0.096 & 1.193 & .233 \\
\hline Muslims in Germany & 0.313 & 0.049 & 6.412 & $<.001$ \\
\hline Alevis in Germany & 0.306 & 0.082 & 3.732 & $<.001$ \\
\hline LGBTI in Germany & 0.136 & 0.057 & 2.399 & .016 \\
\hline LGBT in the United States & 0.141 & 0.071 & 1.982 & .047 \\
\hline
\end{tabular}

Note. For each sample, the difference between the regression coefficient for equality recognition and the coefficient for achievement recognition, or need recognition, respectively, was calculated. These coefficients were taken from the regressions using respect from the general population as the criterion. All $p$-values are for two-tailed tests. 
As presented in Table 3, for most minority groups equality recognition was a significantly stronger predictor than achievement or need recognition, ${ }^{3}$ while for majority groups this was less consistently the case (i.e., amongst majority groups, equality recognition was only in the sample of Catholics in Poland significantly stronger than both achievement and need recognition). ${ }^{4}$

\section{Internal Meta-Analysis}

To get a summary picture of the relationships between respect and the recognition principles, we conducted an internal meta-analysis. We thereby followed the recommendation of Goh, Hall, and Rosenthal (2016), who argue for using an internal meta-analysis to integrate results of one's studies. We conducted a random-effects meta-analysis, using the software package metaSEM (Cheung, 2015) to summarize the regression coefficients for the recognition principles from our individual regression analyses, which had been based on standardized variables.

The meta-analysis revealed that all three links were robust (equality recognition: $b=0.332, S E=0.026,95 \% \mathrm{CI}[0.282$, 0.383], $p<.001$; achievement recognition: $b=0.233, S E=0.017,95 \% \mathrm{CI}[0.199,0.267], p<.001$; need recognition: $b=$ $0.176, S E=0.020,95 \%$ CI $[0.137,0.215], p<.001)$. Furthermore, the link between respect and equality recognition was significantly stronger than the links between respect and the other recognition principles (indicated by $95 \%$-confidence intervals). ${ }^{5}$

\section{Comparison of Recognition Principles Between the Set of Minority Groups and the Set of Majority Groups}

To subject our expectations about differences between minority and majority groups to a test, we analysed whether the relationship between respect and equality recognition was stronger for minority groups than for groups associated with majorities, and whether the relationship between respect and achievement recognition was stronger for groups associated with majority groups than for minority groups. We also analysed the relationship between respect and need recognition.

We conducted a multiple group analysis, in which we constrained the regression coefficients of the three recognition principles. Our constraints specified that the coefficient for equality recognition was set to be equal for all minority groups, resulting in the same coefficient for these groups. Analogously, the coefficient for achievement recognition was set to be equal for minority groups, as well as the coefficient for need recognition. Parallel constraints were applied to the set of majority groups, which resulted in the same coefficient for each recognition principle within the set of majority groups. We then subtracted the values for the majority-related groups from the values for the minority groups and tested the difference values for significance. That way, we tested whether the regression coefficients were different for minority versus majority groups.

For equality recognition, the coefficient for minority groups $(b=0.377, S E=0.018, p<.001)$ was indeed significantly different from that for majority groups $(b=0.292, S E=0.019, p<.001 ; \Delta b=-0.085, S E=0.027, p=.001)$, revealing that for minority groups the link between equality recognition and respect was stronger than it was for groups associated

3) Although all statistical tests reported in the article were routinely two-tailed, our theoretically derived prediction concerning the relative strength of the relationship between respect and equality recognition was directional (i.e., we predicted a stronger link between respect and equality recognition than between respect and the other recognition principles). This prediction was in line with prior studies employing other minority groups. The data thus reliably support our prediction on the conventional level of statistical significance (with alpha set at .05, one-tailed).

4) When repeating the analyses without the control variables, this difference between majorities and minorities emerged even more clearly. While for majorities only in case of Catholics equality recognition was a significantly stronger predictor than achievement recognition and need recognition, for four minorities equality was a stronger predictor than both achievement recognition and need recognition. (However, we consider the analyses that include the control variables as more informative, as they avoid confounds that may distort the effects of the variables of interest.)

5) We also conducted a meta-analysis with separate values for the set of minority groups (equality recognition: $b=0.361, S E=0.031,95 \% \mathrm{CI}[0.301,0.422], p$ $<.001$; achievement recognition: $b=0.219, S E=0.023,95 \% \mathrm{CI}[0.173,0.264], p<.001$; need recognition: $b=0.155, S E=0.023,95 \% \mathrm{CI}[0.110,0.199], p<.001)$ and for the set of majority groups (equality recognition: $b=0.296, S E=0.036,95 \% \mathrm{CI}[0.225,0.366], p<.001$; achievement recognition: $b=0.250, S E=0.024,95 \%$ CI [0.202, 0.297], $p<.001$; need recognition: $b=0.208, S E=0.025,95 \%$ CI $[0.158,0.257], p<.001)$. It was thus corroborated that the difference between equality recognition and the other recognition principles are more pronounced for minority than for majority groups. 
with majorities. For achievement recognition, there was no significant difference between the minority groups $(b=$ $0.223, S E=0.019, p<.001)$ and majority groups $(b=0.253, S E=0.020, p<.001 ; \Delta b=0.030, S E=0.027, p=.273)$. For need recognition, there was a significant difference between minority groups $(b=0.156, S E=0.018, p<.001)$ and majority groups $(b=0.211, S E=0.020, p<.001 ; \Delta b=0.055, S E=0.027, p=.040$ ), revealing that for minority groups the link between respect and need recognition was weaker than for majority groups. ${ }^{6}$

\section{Discussion}

The present research examined the relationship between respect and the three principles of recognition suggested by Honneth (1995), namely equality recognition, achievement recognition, and need recognition. We had hypothesised that for minority group members the link between (perceived) respect and equality recognition is stronger than it is for majority group members. We also assessed whether the links between respect and achievement recognition or need recognition, respectively, differ between minority and majority group members, expecting that for majority group members need recognition is linked more strongly to respect than for minority groups. We approached these questions by two types of comparisons, that is, we compared the link between respect and the three recognition principles within samples as well as between samples.

\section{The Relationship Between Respect and Equality Recognition}

While we observed some variations in the meaning of respect, our internal meta-analysis that combined the regression coefficients of our sampled groups indicated that, in total, respect is most closely related to equality recognition, compared to the other recognition principles. This result suggests that in the context of (post-)modern societies, equality recognition plays a central role in group members' understandings of societal respect.

As we had expected, our results indicated that the relationship between equality recognition and respect was more marked for minority group members than for majority group members. When conducting comparisons within each of the groups, we found that for most minority groups, equality recognition was a significantly stronger predictor than achievement or need recognition, while for majority groups this was less consistently the case. When comparing the absolute strength of the regression coefficients between the set of minority groups and the set of majority groups, we found that respect was more strongly related to equality recognition for minority groups than it was for majority groups. Since ethnic, religious, or sexual minority groups are frequently confronted with discrimination experiences (e.g., Foroutan, 2013; Holtz, Dahinden, \& Wagner, 2013; Huebner, Rebchook, \& Kegeles, 2004), concerns about equality tend to be more prevalent for minority group members than for majority group members (Dovidio et al., 2007). When minority group members' concern for equality recognition translates into demands for more equality recognition, the centrality of equality recognition could influence their understanding of what it means to be respected in society, contributing to the stronger link between equality recognition and respect that we observed.

Additionally, parts of the examined minority groups are likely to perceive their respective minority group as positioned in struggles for recognition. Some participants should be well aware of the public claims and discourses about the struggles their groups are involved in. Social protest movements often phrase their societal experiences as crystallizations of disrespect (see Honneth, 2003). To the extent that they denote experiences of unequal treatment with this term, their understanding of respect corresponds to the understanding of respect as being owed universally by every person, which is widespread in moral philosophy (see Fraser, 2003). Social protest movements can-knowingly or intuitively-base the articulation of their demands on the moral and legal force that is inherent in the equality principle. When members of societal minority groups see their way of life as being threatened by the majority, pointing to violations of basic freedoms constitutes an appeal to the principle of legal equality with its inherent normative strength

6) When repeating the analyses without the control variables, we again found that the regression weight of equality recognition was stronger for minority groups than for majority groups $(p<.001)$. Achievement recognition had a stronger effect for majority than for minority groups, in line with our original hypothesis $(p=.012)$, while need recognition had a marginally stronger effect for majorities than for minorities ( $p=.093$ ). (However, we consider the analyses that include the control variables as more informative, as they avoid confounds that may distort the effects of the variables of interest.) 
(Honneth, 2003). Amongst the three recognition principles examined in the present study, it is especially the equality principle that can exercise leverage for protecting a group's way of life in society, due to its applicability in the sphere of legal relations and its moral weight. The other two recognition principles, namely the achievement and the need principle, in contrast, do not possess this degree of applicability in the context of protecting a group's way of life. The achievement principle would imply that a group's way of life should be recognized due to its unique contributions to society's general values, while the need principle owes its moral force to social relations characterized by loving care (Honneth, 2003). Social movements' demand for respect are therefore more promising and morally compelling when being legitimized by the equality principle. To the degree that societal minorities have based their demands on this moral legitimization, some of their members are likely to be familiar with the semantics that involve a link between respect and equality.

\section{Respect in Relation to the Equality, Achievement, and the Need Principle}

The result that equality recognition is more strongly related to the respect experience of minority members than to that of majority members, while for need recognition it is the other way around, points in a similar direction as a finding from Bergsieker et al. (2010). These authors observed that minority group members had a stronger preference for being respected than to being liked, compared to majority group members. Our observation that the link between respect and equality recognition was stronger for minority group members would then reflect minority members' concern for being respected as equals as opposed to being discriminated in society. Our results, however, go beyond Bergsieker et al. (2010), insofar as we examined the specific meaning of being respected for minority group members and for majority group members.

We could not corroborate our expectation that respect is more closely related to achievement recognition for majority than for minority group members. While one way to justify a privileged position in society could be via references to the group's achievements, the majority group members did not evince a stronger understanding of respect in terms of achievement recognition than minority group members did. A possible interpretation is that the majority group members, who probably take their group's position in society for granted (see Licata et al., 2011; Simon, 2004), did not feel the need to justify their position through achievements. In contrast to minority groups, majority groups are less dependent on the moral force of claims, due to the inherent power imbalances. They might consider their cultural privileges as justified based on, for example, historical continuity. Additionally, the achievement principle is originally conceived as being oriented towards tangible contributions to society, being assessed by the values of society (Honneth, 2003), so that it is not easily applicable when members of a group try to defend their group's specific way of life. As in the case of minorities, the achievement principle is thus of little moral force in connection with demanding respect for a specific group's culture. The achievement principle might therefore be of little use for defending privileges that are related to cultural particularities.

Even if majority group members were inclined to justify claims on the basis of achievement recognition, such a tendency might be matched on the side of minority group members by their own aspirations for achievement recognition. Some societal minority groups are perceived as less competent than the majority, according to the stereotype content model (Fiske, Cuddy, Glick, \& Xu, 2002). Minority group members in our samples might therefore feel more deprived of achievement recognition. Minority group members' reduced ability for claiming achievement recognition might be compensated for by their sensitivity to achievement recognition, so that, as a net effect, minority and majority group members relate respect to achievement recognition to a similar degree.

Instead of a difference in terms of achievement recognition, we observed a non-hypothesized difference with regard to need recognition; that is, the link between respect and need recognition was stronger for majority than for minority group members. This outcome might be related to Bergsieker et al.'s (2010) finding that the motivation for being liked plays a larger role for majority than for minority groups. Our observation that need recognition is more closely associated with respect for majority groups could be interpreted as reflecting majority groups' concerns about being seen by minority groups in a positive light. According to Honneth $(1995,2003)$, the need principle plays a prominent role in social relationships that are characterized by affection. Through this connection between need recognition and 
liking, a heightened sensitivity to being liked could translate into a stronger connection between feeling respected and feeling that one's needs are recognized.

A competing interpretation is that the stronger link between need recognition and respect could reflect majority groups' interests in retaining a privileged position in society. Minority groups' demands for more participation and representation in society challenge the majority group's dominance. When majority groups strive to preserve their privileged position, they are likely to be concerned and suspicious that established politics may focus too much on the "special needs" of minority groups. Majority group members' worry or sensitivity to their own needs could then affect the link between need recognition and respect, to the effect that need recognition gains prominence in majority groups' understanding of what their respected place in society should entail. There is, however, a theoretical challenge to this interpretation, since claims based on the need principle might gain a moral force only in social relationships that are characterised by caring affection (Honneth, 2003). Specific cultural needs that are independent of societal norms cannot necessarily play a moral role on the societal level. Majorities, however, are less dependent on the moral force of claims, as argued above. The observation that the connection between respect and the need principle was stronger for majority groups (than for minority groups) could instead be an expression of a demand that society's traditional cultural imprint is preserved.

Future research is needed to clarify which processes influence the strength of the link between need recognition and respect. That is, it should be examined whether majorities' desire of being liked can translate into a claim for need recognition that becomes blended with a demand for respect, or whether majorities' wishes for defending cultural privileges are expressed as a claim for need recognition which colours majorities' understanding of respect.

\section{Methodological Limitations}

A possible limitation of our study lies in the use of single-item measures of our constructs. To measure respect and the three principles of recognition, participants were asked to what degree they felt respected or recognized by the (respective) population in general. These measures provided conceptual clarity and content validity, as the phrasing of the items used directly the concepts specified in Honneth's $(1995,2001,2003)$ social-philosophical investigations. We acknowledge that single-item measures may suffer from reliability limitations and that it is preferable to measure constructs with multiple items. Future studies should therefore attempt to construct scales with multiple items. However, we wish to highlight that the critical relationship between respect and equality recognition was replicated in our study across a wide range of different samples and contexts.

A further limitation of our research concerns the groups that are associated with majorities in our study. We acknowledge that these groups were not all clear-cut cases. While Catholics in Poland were an obvious majority group, Protestants in Germany and Tea Party supporters in the United States are each a numerical minority. We subsumed these groups under the majority category, since these groups are culturally and ethnically associated with the dominant society and tend to see themselves as representing the majority in the respective societies.

While Protestants in Germany are a numerical majority group in some states of Germany, Tea Party supporters are usually in a position of a numerical minority. We therefore tested the robustness of our finding on the differences between minority and majority groups by omitting the sample of Tea Party supporters. Our results corroborated the observed pattern. That is, the link between equality recognition and respect was still stronger for the minority groups than it was for the two remaining majority groups $(\Delta b=-0.083, S E=0.029, p=.004)$. For achievement recognition, there was still no significant difference between the minority and majority groups $(\Delta b=0.046, S E=0.029, p=.118)$. For need recognition, the link was still stronger for majority groups $(\Delta b=0.070, S E=0.029, p=.017)$.

To test the generalizability of the findings, future research should analyse to what degree the pattern of results that we observed can be replicated with other numerical majorities.

\section{Idiosyncrasies of the Sampled Groups}

In addition to the general differences observed between majority and minority groups in our samples, there were also some particularities in the specific samples. 
Protestants in Germany stood out, being the only sample for which the regression weight for equality recognition was lower than that for achievement recognition. When speculating about this particularity, one possible starting point is Weber's (1905) classical writing that coined the term "Protestant Work Ethic". Analysing the number of working hours in Germany, Spenkuch (2017) found that individuals work longer hours in geographical areas with a Protestant history compared with individuals in areas with a Catholic history. If Protestants in Germany were even today more oriented towards achievement (either for reasons of their individual beliefs or due to the regional culture), this orientation could induce an increased sensitivity to achievement. A heightened perceived importance of achievement could be responsible for our observation that perceived respect was more dependent on the recognition of this group's achievements than on equality recognition.

With regard to the absolute level of the regression weights for equality, the samples with the highest regression weights were Muslims in Germany, Alevis in Germany, and Catholics in Poland. For Muslims and Alevis in Germany, this result is in line with the expectation that equality recognition is particularly important for groups with a minority position and a history of disadvantages. Muslims in Germany are frequently confronted with rejection (Foroutan, 2013; Holtz at al., 2013). Such discrimination experiences, which represent a strong challenge to a group's belongingness to society, are likely to entail a high sensitivity to equality.

Given that Catholics in Poland are in a position of a marked numerical majority, it appears, at first glance, surprising that the regression weight for equality was also high. A conceivable explanation derives from the fact that in Poland being Polish is closely interwoven with being Catholic (Porter-Szücs, 2011). Reasons for this close connection might be found in Poland's former relations to its neighbouring states. Prussia or Germany and Russia occupied Poland several times, possibly highlighting religious specificities (Borowik, 2002, 2010). (Prussia was predominantly Protestant and Russia predominantly Orthodox.) These foreign occupations were moreover partially interpreted in religious terms, assigning meaning to the Polish fate by relating it to the suffering of Christ, claiming that Poland atones on behalf of other nations (Bar-Tal, Chernyak-Hai, Schori, \& Gundar, 2009; Jasińska-Kania, 2007). Such religious interpretations probably tightened the connection between being Polish and being Catholic. Additionally, during communism Catholicism had to assert its standing when faced with an ideology that threatened the status of religion. Owing to the close connection between being Catholic and being Polish, feeling respected by society could assume a special meaning. When society is not clearly distinguishable from the own group, the question about societal respect could become a question of ingroup respect. The special role of equality recognition observed for Catholics in Poland thus is compatible with other research suggesting that, within ingroup contexts, respect is mainly defined by equality recognition (Simon, Brause, \& Galeão-Silva, 2016). Additionally, a history of occupations might have underlined the importance of equality.

\section{Conclusion}

Given the high prevalence of demands for respect in societal intergroup conflicts, arriving at a better understanding of the meaning of respect is pertinent for the analysis of intergroup relations. In our meta-analysis, equality recognition was the strongest predictor, relative to achievement and need recognition, in the experience of respect. This suggests that groups' demands for respect might often be addressed by a political and societal framework in which groups' equal rights are manifested in explicit and implicit norms of mutual treatment, possibly supplemented by addressing achievement and need recognition, depending on specific contexts.

We also identified variations in the meaning of respect as a function of people's membership in minority versus majority groups. We had hypothesized that members of minority groups would be particularly sensitive to (the lack of) equality recognition, owing to their increased vulnerability to disadvantages associated with their minority position in society. We indeed found that equality recognition played a more important role in the experience of respect among members of minority groups than among members associated with majority groups. Thus, for minority groups, demands for respect might be especially strongly related to demands for equality recognition. Given the moral force of the equality principle, this result might partially reflect that minorities can maintain their way of life and improve their societal position most effectively through references to equality.

There was also the indication that need recognition is of more significance for majority groups than for minority groups. This might suggest that for majority groups needs concerning the preservation of the dominant culture are of 
special importance. A competing explanation is based on the observation that majority groups have a greater concern about being liked (Bergsieker et al., 2010), in combination with the notion that affection is linked to need recognition (Honneth, 1995). More research is needed to uncover the exact processes underlying the link of need recognition and respect.

Overall, our results indicate that most groups in (post-)modern societies understand respect more as equality recognition than achievement or need recognition. This empirical observation resonates well with a conceptualization of respect that revolves around the equality principle. Accordingly, demands for respect might be addressed by establishing relationships in society that are based on the mutual recognition as equals, embodied in formal rights and in informal norms of mutual treatment. Additionally, both achievement and need recognition were revealed to have some role in the experience of being respected. In contrast to equality recognition, achievement and need recognition give less room for symmetrical recognition on a societal level, as these latter principles of recognition are more oriented towards the particularities of societal groups or individuals. Honneth (1995), however, indicates that societies can develop shared values that are sufficiently open and pluralistic to allow for different forms of self-actualization, so that all members of society have the chance to receive achievement recognition according to their specific capabilities. Regarding need recognition, those general needs which are shared in society are obviously not very problematic, insofar as they allow for symmetrical recognition relations. More challenging is the situation when societal groups make claims concerning needs that are specific to a societal group. To the degree that these particularities are not violating basic societal norms (like solidarity and equality of rights; see Habermas, 1996, 2004), societies can give room for these specificities and make some concessions to societal groups so that they can maintain their ways of life (see Taylor, 1994).

Funding: The research was made possible by German Research Foundation (DFG) Grant SI 428/20-1.

Acknowledgments: The authors have no support to report.

Competing Interests: The authors have declared that no competing interests exist.

Data Availability: The research data and analyses syntaxes used for this article will be made available to scholars with legitimate reasons, upon contact with the corresponding author.

\section{Supplementary Materials}

The Supplementary Materials contain the following items (for access see Index of Supplementary Materials below):

- Online Appendix A: Original items used in the studies and their English translations

- Online Appendix B: Means, standard deviations, and intercorrelations for the main variables

Index of Supplementary Materials

Schaefer, C. D., Zitzmann, S., Loreth, L., Paffrath, J., Grabow, H., Loewy, M., \& Simon, B. (2021). Supplementary materials to "The meaning of respect under varying context conditions" [Additional information]. PsychOpen GOLD.

https://doi.org/10.23668/psycharchives.5165

\section{References}

Aydin, A. L., Ullrich, J., Siem, B., Locke, K. D., \& Shnabel, N. (2019). Agentic and communal interaction goals in conflictual intergroup relations. Fournal of Social and Political Psychology, 7, 144-171. https://doi.org/10.5964/jspp.v7i1.746

Bar-Tal, D., Chernyak-Hai, L., Schori, N., \& Gundar, A. (2009). A sense of self-perceived collective victimhood in intractable conflicts. International Review of the Red Cross, 91(874), 229-258. https://doi.org/10.1017/S1816383109990221 
Bergsieker, H. B., Shelton, J. N., \& Richeson, J. A. (2010). To be liked versus respected: Divergent goals in interracial interactions. Journal of Personality and Social Psychology, 99, 248-264. https://doi.org/10.1037/a0018474

Borowik, I. (2002). The Roman Catholic church in the process of democratic transformation: The case of Poland. Social Compass, 49(2), 239-252. https://doi.org/10.1177/0037768602049002008

Borowik, I. (2010). Why has religiosity in Poland not changed since 1989? Five hypotheses. Politics and Religion, 3(2), $262-275$. https://doi.org/10.1017/S1755048310000064

Cheung, M. W. L. (2015). Meta-analysis: A structural equation modeling approach. Chichester, United Kingdom: Wiley.

Deutsch, M. (1975). Equity, equality, and need: What determines which value will be used as the basis of distributive justice? The fournal of Social Issues, 31(3), 137-149. https://doi.org/10.1111/j.1540-4560.1975.tb01000.x

Dovidio, J. F., Gaertner, S. L., \& Saguy, T. (2007). Another view of "we”: Majority and minority group perspectives on a common ingroup identity. European Review of Social Psychology, 18, 296-330. https://doi.org/10.1080/10463280701726132

Foroutan, N. (2013). Identity and (Muslim) integration in Germany. Washington, DC, USA: Migration Policy Institute.

Fiske, S. T., Cuddy, A. J. C., Glick, P., \& Xu, J. (2002). A model of (often mixed) stereotype content: Competence and warmth respectively follow from perceived status and competition. fournal of Personality and Social Psychology, 82(6), 878-902. https://doi.org/10.1037/0022-3514.82.6.878

Fraser, N. (2003). Social justice in the age of identity politics: Redistribution, recognition, and participation. In N. Fraser \& A. Honneth (Eds.; J. Golb, J. Ingram, C. Wilke, Trans.), Redistribution or recognition: A political-philosophical exchange (pp. 7-109). London, United Kingdom: Verso.

Goh, J. X., Hall, J. A., \& Rosenthal, R. (2016). Mini meta-analysis of your own studies: Some arguments on why and a primer on how. Social and Personality Psychology Compass, 10, 535-549. https://doi.org/10.1111/spc3.12267

Habermas, J. (1996). Die Einbeziehung des anderen. Studien zur politischen Theorie [The inclusion of the other: Studies in political theory]. Frankfurt a. M., Germany: Suhrkamp.

Habermas, J. (2004). Wahrheit und Rechtfertigung: Philosophische Aufsätze. Erweiterte Ausgabe. [Truth and justification: Philosophical essays. Extended edition]. Frankfurt a. M., Germany: Suhrkamp.

Hegel, G. W. F. (1969). Jenaer Realphilosophie. Hamburg, Germany: Felix Meiner. (Original work published 1805-1806)

Holtz, P., Dahinden, J., \& Wagner, W. (2013). German Muslims and the "integration debate": Negotiating identities in the face of discrimination. Integrative Psychological \& Behavioral Science, 47, 231-248. https://doi.org/10.1007/s12124-012-9227-6

Honneth, A. (1995). The struggle for recognition. Cambridge, United Kingdom: Polity Press.

Honneth, A. (2001). Redistribution or recognition? Theory, Culture \& Society, 18, 43-55. https://doi.org/10.1177/02632760122051779

Honneth, A. (2003). Redistribution as recognition: A response to Nancy Fraser. In N. Fraser \& A. Honneth (Eds.; J. Golb, J. Ingram, \& C. Wilke, Trans.), Redistribution or recognition: A political-philosophical exchange (pp. 110-197). London, United Kingdom: Verso.

Huebner, D. M., Rebchook, G. M., \& Kegeles, S. M. (2004). Experiences of harassment, discrimination, and physical violence among young gay and bisexual men. American fournal of Public Health, 94, 1200-1203. https://doi.org/10.2105/AJPH.94.7.1200

Inglehart, R., \& Norris, P. (2003). The true clash of civilizations. Foreign Policy, 135, 63-70.

Jasińska-Kania, A. (2007). Bloody revenge in “God's playground”: Poles' collective memory of relations with Germans, Russians, and Jews. International fournal of Sociology, 37(1), 30-42. https://doi.org/10.2753/IJS0020-7659370102

Kant, I. (1974). Grundlegung zur Metaphysik der Sitten [Groundwork of the metaphysics of morals]. Frankfurt a. M., Germany: Suhrkamp. (Original work published 1785)

Kaplan, I. (2013). Glaubensgrundlagen und Identitätsfindung im Alevitentum [Statements of faith and the determination of identity in Alevism]. In F. Eißler (Ed.), Aleviten in Deutschland: Grundlagen, Veränderungsprozesse, Perspektiven (2nd ed., pp. 29-76). Berlin, Germany: Evangelische Zentralstelle für Weltanschauung.

Licata, L., Sanchez-Mazas, M., \& Green, E. G. T. (2011). Identity, immigration, and prejudice in Europe: A recognition approach. In S. J. Schwartz, K. Luyckx, \& V. L. Vignoles (Eds.), Handbook of identity theory and research, Volume 2: Domains and categories (pp. 895916). New York, NY, USA: Springer.

Muthén, L. K., \& Muthén, B. O. (1998-2010). Mplus User's Guide (6th ed.). Los Angeles, CA, USA: Author.

Paffrath, J., \& Simon, B. (2020). Dis-embedded identity of majority members: The case of Catholics in Poland. Manuscript submitted for publication.

Parekh, B. (2008). A new politics of identity: Political principles for an interdependent world. Basingstoke, United Kingdom: Palgrave Macmillan. 
Porter-Szücs, B. (2011). Faith and fatherland: Catholicism, modernity, and Poland. Oxford, United Kingdom: Oxford University Press.

Renger, D., \& Simon, B. (2011). Social recognition as an equal: The role of equality-based respect in group life. European fournal of Social Psychology, 41, 501-507. https://doi.org/10.1002/ejsp.814

Schaefer, C. D., \& Simon, B. (2020). Muslims' experiences of equality recognition in Germany: Effects on identification with the larger society and on equality recognition of other societal subgroups. Cultural Diversity \& Ethnic Minority Psychology, 26, 32-41. https://doi.org/10.1037/cdp0000270

Shnabel, N., \& Nadler, A. (2008). A needs-based model of reconciliation: Satisfying the differential emotional needs of victim and perpetrator as a key to promoting reconciliation. Journal of Personality and Social Psychology, 94, 116-132.

https://doi.org/10.1037/0022-3514.94.1.116

Simon, B. (2004). Identity in modern society. Oxford, United Kingdom: Blackwell.

Simon, B. (2017). Grundriss einer sozialpsychologischen Respekttheorie: Implikationen für Kooperation und Konflikt in pluralistischen Gesellschaften [Outline of a social psychological theory of respect: Implications for cooperation and conflict in pluralistic societies]. Psychologische Rundschau, 68, 241-250. https://doi.org/10.1026/0033-3042/a000326

Simon, B., Brause, A.-C., \& Galeão-Silva, L. G. (2016). Contextualizing the meaning of respect: The case of evangelicals in Brazil / Contextualización del significado del respeto: El caso de la comunidad evangélica de Brasil. Revista de Psicología Social / International fournal of Social Psychology, 31, 399-422.

Simon, B., Eschert, S., Schaefer, C. D., Reininger, K. M., Zitzmann, S., \& Smith, H. J. (2019). Disapproved, but tolerated: The role of respect in outgroup tolerance. Personality and Social Psychology Bulletin, 45, 406-415. https://doi.org/10.1177/0146167218787810

Simon, B., \& Grabow, H. (2014). To be respected and to respect: The challenge of mutual respect in intergroup relations. British fournal of Social Psychology, 53, 39-53. https://doi.org/10.1111/bjso.12019

Simon, B., Grabow, H., \& Böhme, N. (2015). On the meaning of respect for sexual minorities: The case of gays and lesbians. Psychology and Sexuality, 6, 297-310. https://doi.org/10.1080/19419899.2014.987683

Simon, B., Reininger, K. M., Schaefer, C. D., Zitzmann, S., \& Krys, S. (2019). Politicization as an antecedent of polarization: Evidence from two different political and national contexts. British fournal of Social Psychology, 58, 769-785.

https://doi.org/10.1111/bjso.12307

Simon, B., \& Schaefer, C. D. (2016). Tolerance as a function of disapproval and respect: The case of Muslims. British fournal of Social Psychology, 55, 375-383. https://doi.org/10.1111/bjso.12137

Simon, B., \& Schaefer, C. D. (2018). Muslims' tolerance towards outgroups: Longitudinal evidence for the role of respect. British fournal of Social Psychology, 57, 240-249. https://doi.org/10.1111/bjso.12213

Spenkuch, J. L. (2017). Religion and work: Micro evidence from contemporary Germany. fournal of Economic Behavior \& Organization, 135, 193-214. https://doi.org/10.1016/j.jebo.2017.01.011

Taylor, C. (1994). Multiculturalism: Examining the politics of recognition. Princeton, NJ, USA: Princeton University Press.

Weber, M. (1905). The Protestant ethic and the spirit of capitalism. New York, NY, USA: Scribners.

Zitzmann, S., Loreth, L., Reininger, K. M., \& Simon, B. (2021). Does respect foster tolerance? (Re)analyzing and synthesizing data from a large research project using meta-analytic techniques. Personality and Social Psychology Bulletin. Advance online publication. https://doi.org/10.1177/01461672211024422 